\title{
New Approach for Examination of Pattern Evidences: Cases study
}

\author{
Sharma $\mathrm{M}^{* 1}$ and Jha $\mathrm{S}^{2}$ \\ ${ }^{1}$ In-Charge, Mobile Forensic Science Unit, Bharatpur, Senior Scientific Officer (Physics Division), Regional FSL, \\ Bharatpur (Raj.), India \\ ${ }^{2}$ Dy. Director (Physics Division), State FSL, Jaipur, India
}

${ }^{*}$ Corresponding author: Sharma M, In-Charge, Mobile Forensic Science Unit, Bharatpur, Senior Scientific Officer (Physics Division), Regional FSL, Bharatpur (Raj.), India, E-mail: mksphy@gmail.com

Citation: Sharma M, Jha S (2016) New Approach for Examination of Pattern Evidences: Cases study. J Forensic Sci Criminol 4(2): 203

Received Date: February 16, 2016 Accepted Date: April 27, 2016 Published Date: April 28, 2016

\begin{abstract}
Improvement in technology has changed the techniques and pattern of examination of the physical evidences. The technology based gazettes like PDA, Computer and digital camera has improved the process of examination and speed of file-work while examination. Two different types of case exhibits and their pattern of examination in physics point-of-view, how the technology changes the hierarchy of old pattern.

From the cases study, importance of new technology is exemplified, using the latest technique, computer based software to examine the exhibit. Importance in cases related to footwear impression, tyre-tread mark and tool marks analysis are reported.

Keywords: Pattern Evidence; Technology; Footwear impression; Tool marks Analysis
\end{abstract}

\section{Introduction}

During the last decade, inexpensive yet powerful digital computers and tools have become widely available and have been applied to a multitude of tasks. By hitching computers with imaging detectors and displays, very capable systems for creating and analyzing imagery have been constructed and are being applied in many arenas.

For example, they now are used to reconstruct x-ray and magnetic resonance images in medicine, to analyze multi-spectral aerial and satellite images for environmental and military uses, to read Universal Product Codes that specify products and prices in retail stores, just to name a few [1-3]. A forensic evidence analyst may be defined as a forensic scientist concerned with the characterization, identification, and comparison of microscopic materials in criminal cases. Trace evidence helps solve crimes by linking people, places, and things involved in a crime. By the microscopic materials they share through and proper analysis methodology gives the way to justice.

Through this paper authors have investigated the basic principles and introductory applications of digital imaging systems, and include many simple examples to illustrate the concepts using some software like Canvas, Photoshop and Corel Draw and how these tools can be used in the Forensic examinations at spot as well as in the lab [4-6].

\section{Materials and Methods}

The examination of physical evidence by a forensic scientist is generally undertaken for the purposes of identification or comparison [7].

Comparison: The process of ascertaining whether two or more objects have a common origin. A comparison analysis subjects a suspect specimen and a standard/reference specimen to the same tests and examinations for the ultimate purpose of determining whether they have a common origin.

Compare in cases related to: 1) Hair found at a scene to hair from a suspect

2) A paint chip found at a scene with the paint from a suspect vehicle

3) Fibers found on a victim with fibers found in suspect's back seat.

Forensic Comparison is a two-step procedure 
a) Combinations of select properties are chosen from the suspect and standard/reference specimen for comparison.

b) These will depend on the nature of the specimens being compared.

To comprehend the evidential value of a comparison, one must appreciate the role that probability has in ascertaining the origins of two or more specimens [8-10]. Proposed cases studies in this article are purely new and specific, we suggest reader to study as basic methodologies and techniques readily available in literature [11-13].

\section{Cases Study}

\section{Footwear and tyre tread impressions examinations using software [3]}

\section{Footwear impression:}

\section{Tool Required: PC, CorelDraw13 / Adobe PhotoShop CS3 and Digital Camera}

Many researchers have recently been examining how automated computer systems could help police search and match shoeprint in order to link suspects to crime scenes. Bodziak is one of the leading authorities in the area of manual human shoeprint classification [9]. He described the process of detection, recovery and examination of footwear impression evidence.

The subject of shoe prints examinations are images of soles left by the perpetrator on surfaces such as floor, carpet, soil, pavement and street. In Table 1 summary of the two shoes print comparison with the help of Corel Draw Software and Canvas 9 software. From Table 1, one can easily conclude that the shoe print belongs to the same shoe. The accuracy level of distances measured my human is two point where using software's the accuracy upgraded as four point after decimal is being achieved.

\begin{tabular}{|c|c|c|c|c|}
\hline \multirow{2}{*}{$\begin{array}{c}\text { Name of the drawn line } \\
\text { on the Point considered in } \\
\text { footwear impression }\end{array}$} & $\begin{array}{c}\text { Original shoe print on Grey scale in Corel } \\
\text { Draw }\end{array}$ & \multicolumn{2}{c|}{$\begin{array}{c}\text { Shoe print lifted from the scene of } \\
\text { occurrence on grey scale on Corel Draw }\end{array}$} \\
\cline { 2 - 5 } & $\begin{array}{c}\text { Selection } \\
\text { width/length }\end{array}$ & Angle rotation & $\begin{array}{c}\text { Selection } \\
\text { width/length }\end{array}$ & Angle rotation \\
\hline $\mathrm{A}$ & $6.97158^{\prime \prime}$ & $90.728^{\circ}$ & $6.97158^{\prime \prime}$ & $90.728^{\circ}$ \\
\hline $\mathrm{B}$ & $2.93682^{\prime \prime}$ & $0.0^{\circ}$ & $2.93687^{\prime \prime}$ & $0.0^{\circ}$ \\
\hline $\mathrm{C}$ & $2.10565^{\prime \prime}$ & $0.0^{\circ}$ & $2.10562^{\prime \prime}$ & $0.0^{\circ}$ \\
\hline D & $6.54662^{\prime \prime}$ & & \\
\hline \multirow{2}{*}{$\begin{array}{c}\text { Photograph of the footwear } \\
\text { impression }\end{array}$} & & & \\
\hline
\end{tabular}

Table 1: Summary of two footwear sole comparison

\section{Tyre-Tread impressions:}

\section{Tool required: PC, CorelDraw 13 and Digital Camera}

In this case study, one person was died at the spot and the accidented motorcycle was hide, by the perosn from whom the motorcycle was collide. The tyre treat impression on the gravel sand road, was not sufficient clear, but on behalf of the digital camera, we are able to trace the direction of motorcyle was hidden, by the road side. The impression was compared with the corel draw X3 software. One can easily conclude that the direction of vehicles before/after accidnet on the basis of the direction of the tyre tread impressions on the spot of occurrence Figure 1(a-f). 


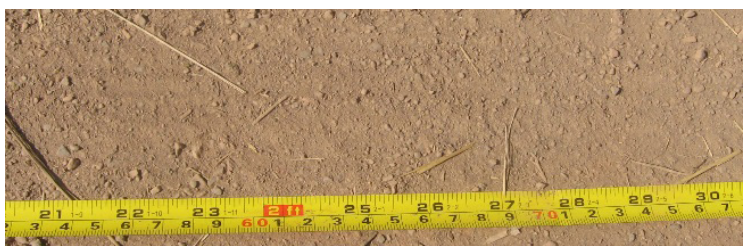

(a) Original Image of front tyre on the road



(c) Corrected \& analyzed image of front tyre
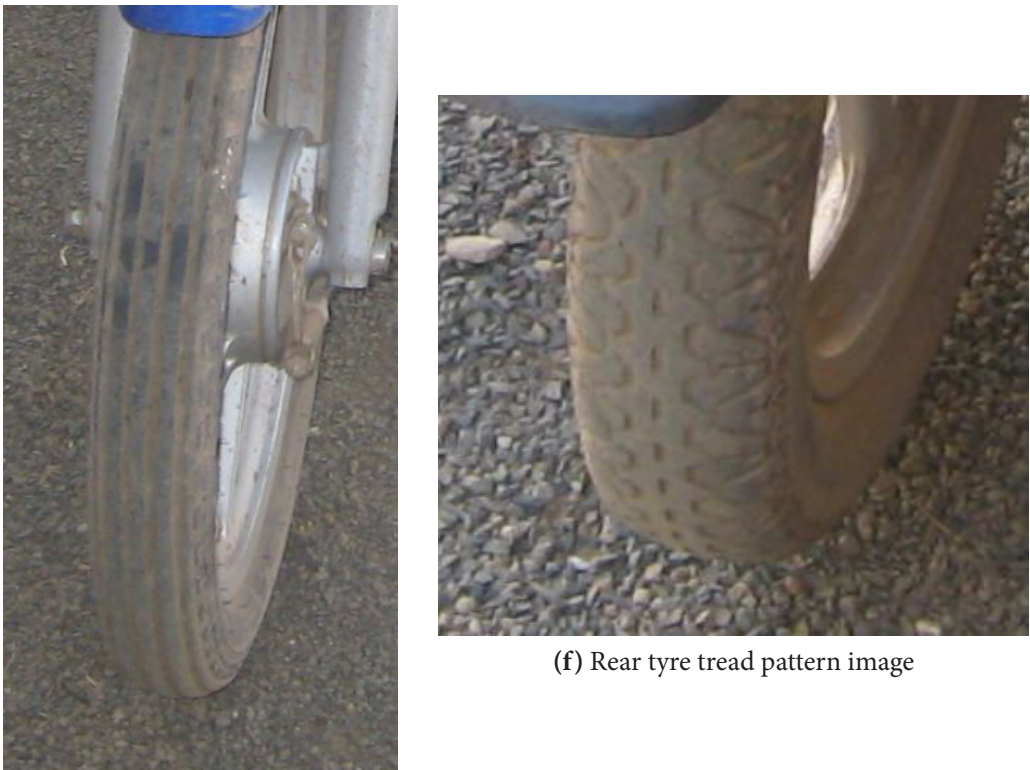

(f) Rear tyre tread pattern image

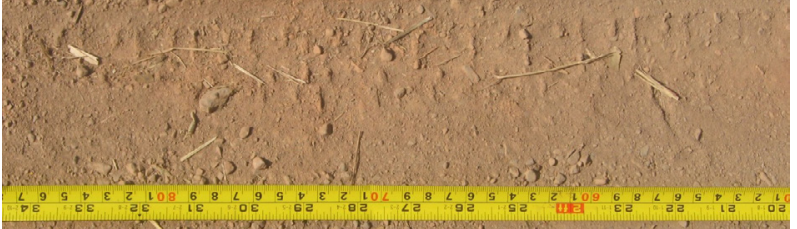

(b) Original Image of rear tyre on the road



(d) Corrected \& analyzed image of rear tyre

(e) Front tyre tread pattern image

Figure 1(a-f): The case study showing the usefulness of the technology in on-hand investigation at the spot as well as at the laboratory examinations

\section{Tool marks Analysis:}

Tool marks or marks of objects that have been used as tools are often found on stolen vehicles/houses entry point. Among the tools that leave identifiable marks are axes, knives, screwdrivers, chisels, crowbars, pliers, and cutters. In general, the tool marks are a result of the action of entering and/or starting the point of the area. The best places to find these tool marks are on or around the different locks present on the houses/vehicle (doors, trunk, or ignition). To collect these marks, it is best to take the entire lock back to the laboratory. This allows the tool mark examiner to have sufficient time to study the object and to make the most appropriate comparisons with any suspected tools. Casting or other methods of taking impressions of a tool mark should be used when it is not possible to collect the object onto which the marks are present. In this study we have proposed the proper digital photographic analysis for tool marks.

Tool marks request is for the examination of a tool and a surface suspected of having been contacted by the tool to determine the presence of unique microscopic characteristics on the surface imparted to it by the tool. The use cause tools to bear unique microscopic characteristics. Under certain conditions these characteristics can be imparted to surfaces contacted by tools. Submitted tools should be able to produce the mark in question and have a suspect associated with them. However, the evidence mark be submitted whenever possible. The examination of tool marks is very important at the scene of occurrence and in the laboratory too.

But new technology and software are providing a new ground and support to the forensic community to learn, enhance and propagate the technique to the experts, which help in analysis the tool marks. Through the cases study on three different tool marks one case easily evaluate that the tool marks analysis gives the proper direction of investigation and case being solved on behalf of that. 
Case Study: In Figure 2 (a) window of a temple has been shown, where a broken piece of hacksaw blade is appeared.

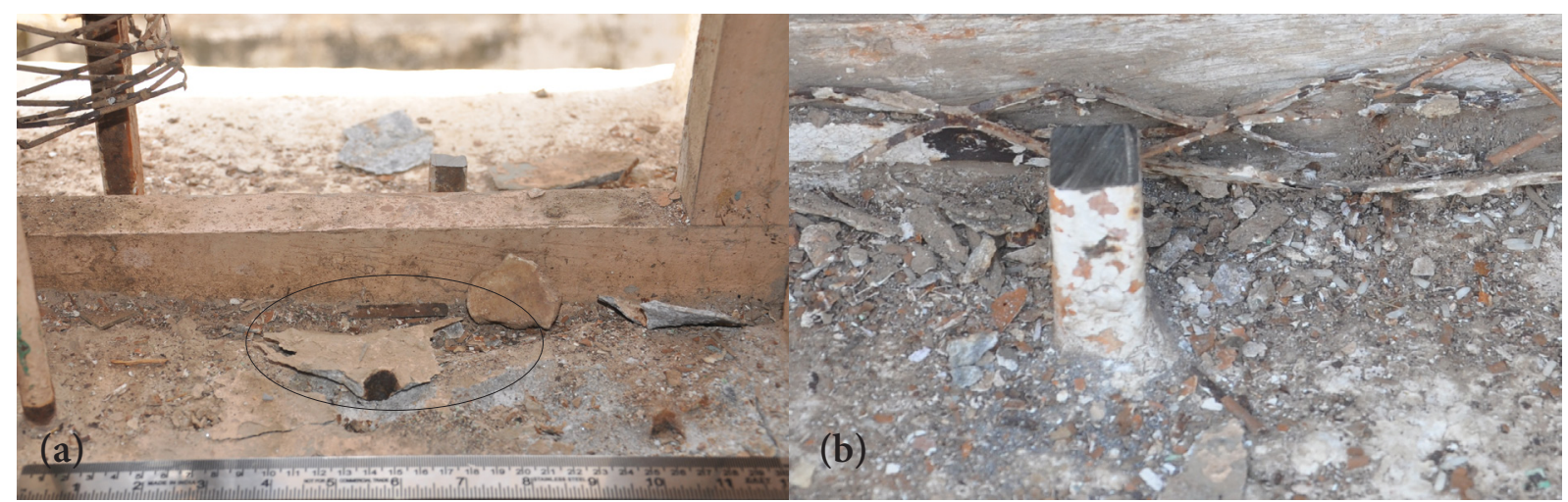

Figure 2: (a) The window showing the location of the metallic rod where the thieves have entered. Ring showing the location of the broken piece of hack-saw blade. (b) Closer view of the cut pieces

From the pattern on the cut character and striation marks on the both surfaces proving the use of hack-saw blade has been ruled out trough this observation the IO able to trace the planner of this theft

From the Figure 2 and 3, it is clearly demonstrated that no need of further examination, for further examination all the exhibits have been forwarded to the laboratory.
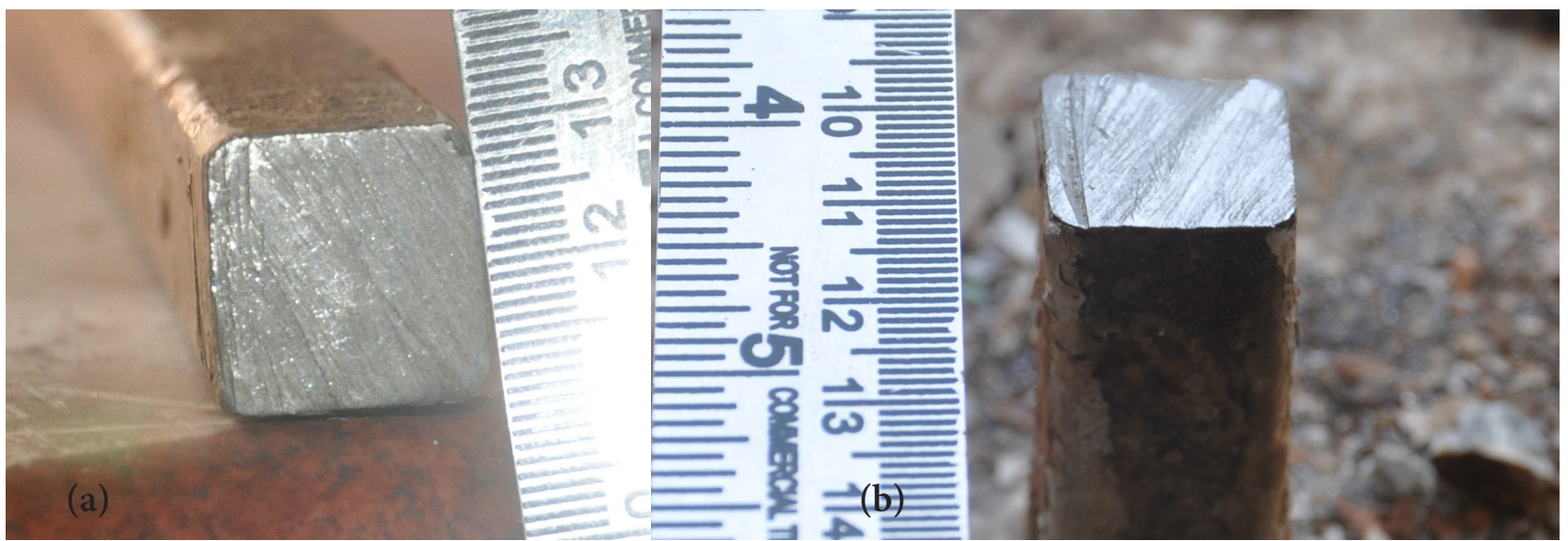

Figure 3: (a) Cut end of the part of the rod found somewhere at the spot of hack-saw blade. (b) Closer view of the cut pieces attached to the window

\section{Results and Discussion}

The performed shoeprint, tyre-tread impression and tool marks showed that there is a possibility of per forming comparative analyses even on such difficult material as on different surfaces using software like CorelDraw and Canvas. For forensic scientists, it is often interesting to establish whether the investigated shoeprint has already been photographed. The results of this study could therefore be exploited in the future to test the ability of the method to find the same or similar techniques in the images database and the evaluation would in this case be done using different photographs of SOC to test the retrieval in the database.

\section{References}

1. Berg E (1994) Latent Image Processing - A changing technology The Pacific NW IAI Examiner 12-5.

2. Sharma M, Jha S (2010) Uses of software in Digital Image Analysis: a Forensic Report at Proceedings of ICDIP, SPIE.

3. Dalrymple B (1994) Computer Enhancement of Evidence through Background Noise Suppression. J Forensic Sci 39: 537-46.

4. http://www.corel.com

5. http://www.adobe.com/downloads/

6. Bouton GD, Bouton B (1995) Inside Adobe Photoshop CS3, New Riders Publishing, New York.

7. Geberth VJ (1996) Practical homicide investigation tactics, procedures and forensic techniques, $3^{\text {rd }}$ ed, CRC Press, Boca Raton, FL.

8. Palenik SJ (1982) Microscopic Trace Evidence - The Overlooked Clue. Microscope 30: 163-9.

9. Blizter HL, Jacobia J (2002) Forensic digital imaging and photography, Academic Press, London, England.

10. Rudram DA (1996) Interpretation of scientific evidence. Sci Justice 36: 133-8.

11. Bodziak WJ (2008) Footwear Impression Evidence, $2^{\text {nd }}$ ed, CRC Press Taylor \& Francis Group 6000 Broken Sound Parkway NW, Suite 300 Boca Raton, FL. 
12. Houck M (2001) Mute Witnesses - Trace Evidence Analysis. New York: Academic Press.

13. Petraco N (1986) Trace evidence - the invisible witness. J Forensic Sci 31: 321-8.

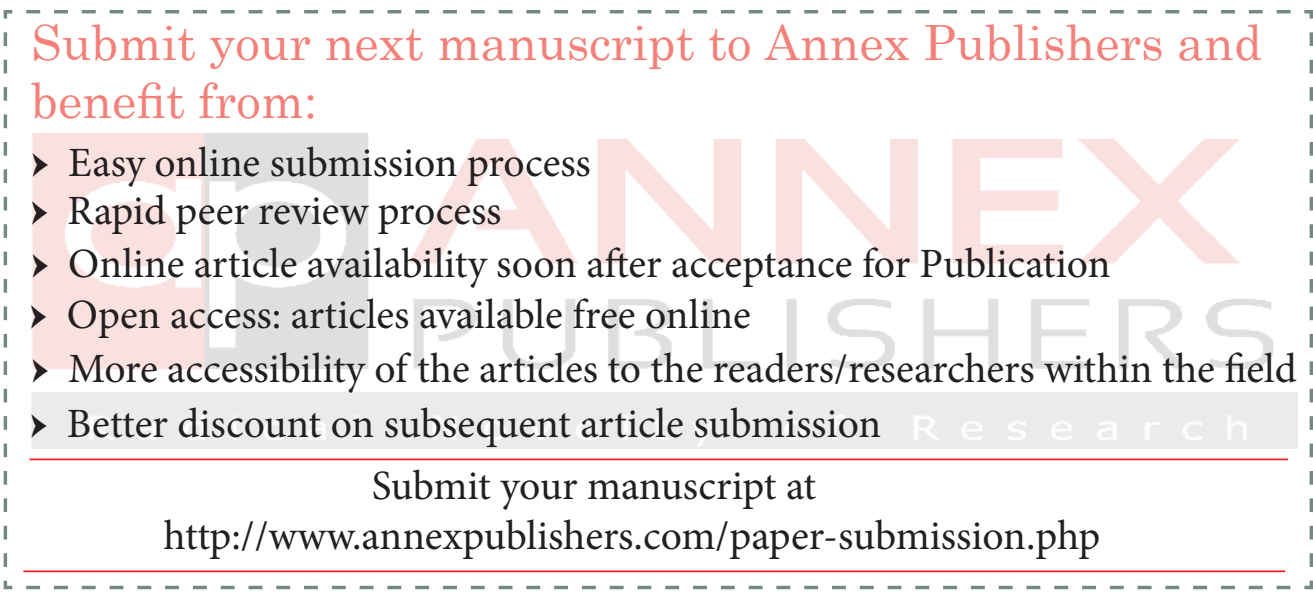

